الإتجاهات الغذائية و السلوك الغذائى للاعبى كرة السلة بالدورى الممتاز .

$$
\begin{aligned}
& \text { أســـد علـى أحـــد الكبـكي } \\
& \text { قسم تدريب الالعاب الرياضية ـ كلية التربية الرياضية للبنين - جامعة الإسكندرية. }
\end{aligned}
$$

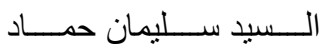

المقدمة ومشكلة البحث

مما لا شك فيه أن البر امج الغذائية للرياضيين لا تقل أهمية عن بر امج التدريب، حيث أن البر امج الغذائيسة السليمة في

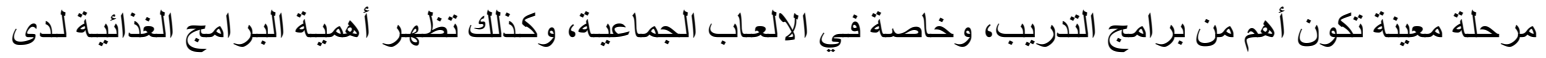

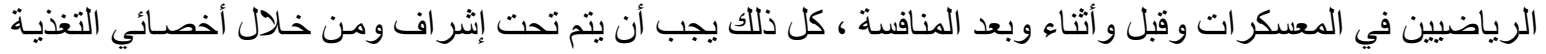

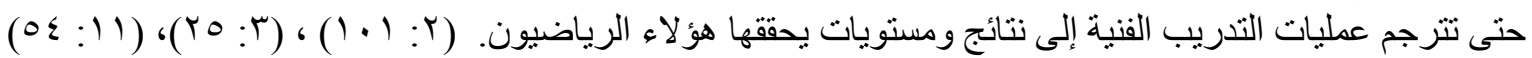
وقد أثنتت الدر اسات على مر السنين منذ بداية الاهنمام بالتغذية الرياضية أن السلوك الغذائى السليم يرتبط ارتباطـاً وثثيقاً

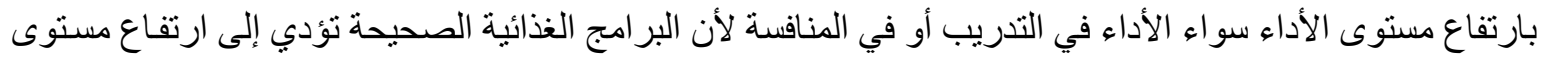

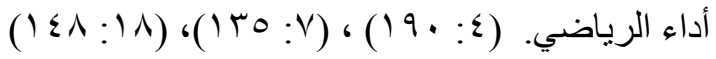

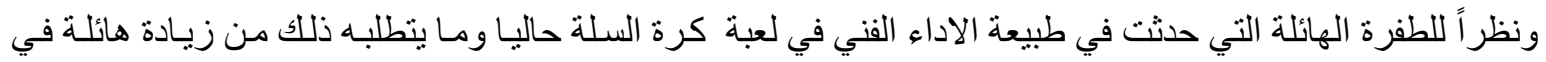

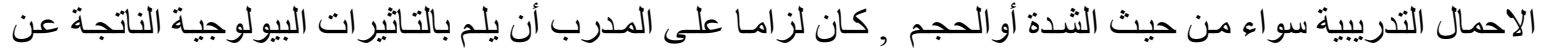

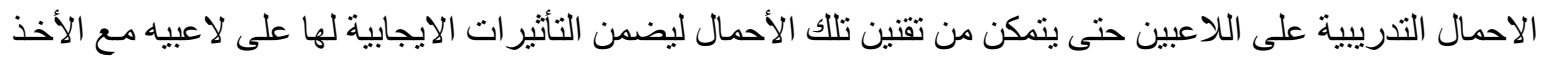
في الإعتبار تنظيم التغذية الصحية السليمة.

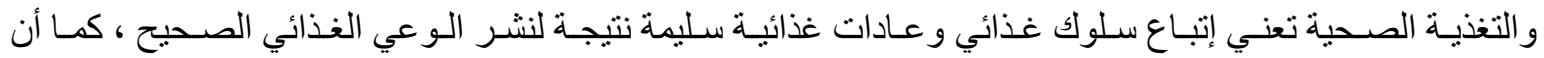

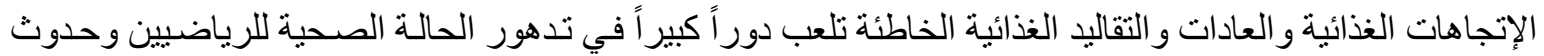

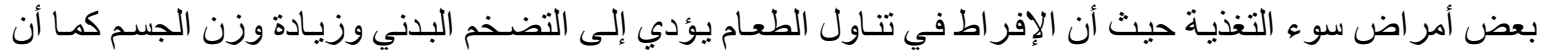

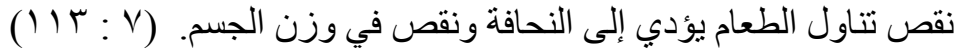

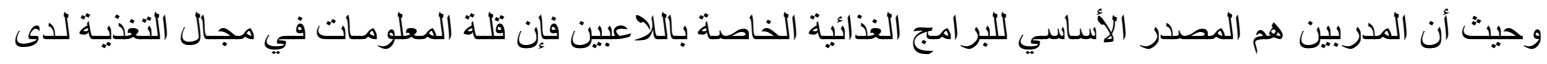

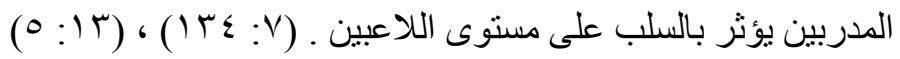
ويؤثر الوعي الغذائي للرياضبين على مدى تطوير الإتجاهـات الغذائية والسلوك الغذائى حيث أن الاتجاهـات محرك

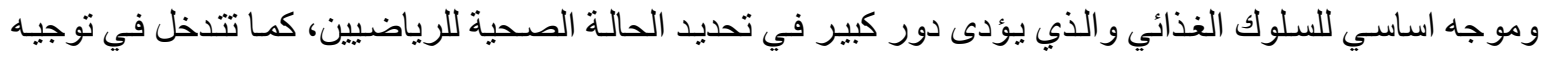

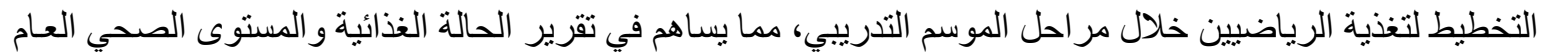

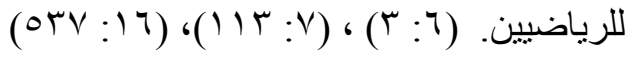
و السلوكيات الغذائية الخاطئة من الصعب تغيير ها إلا على مدى سنوات طويلة، فعن طريق التوعية ونشر التقافة الغذائية

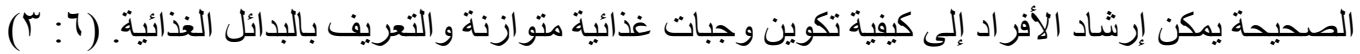

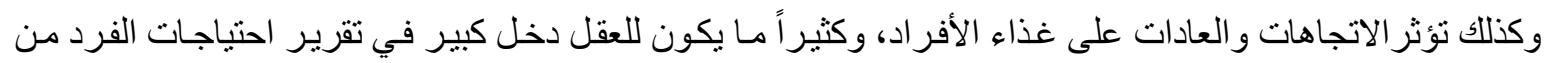

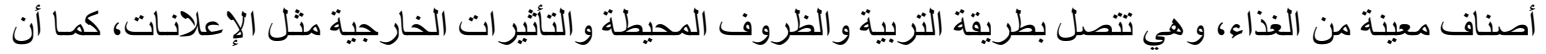

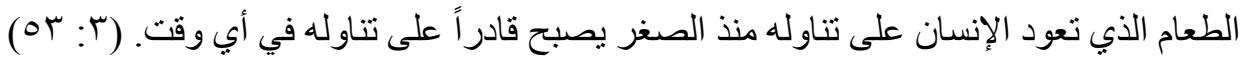




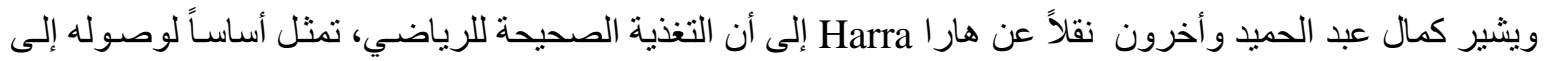

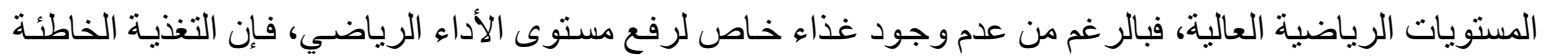

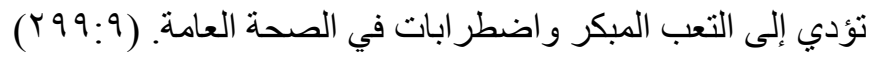

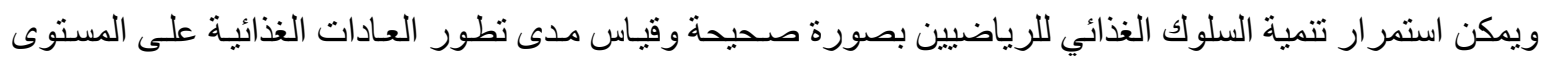

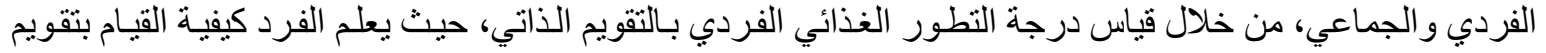

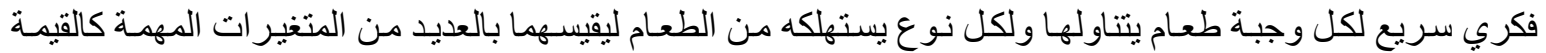

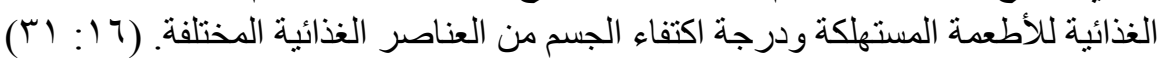
ويذكر روناللد وبرينت Roland and Brent أن النظـام الغذائي الخـاص بـاللاعبين يلعب دوراً أساسياً في الأداء

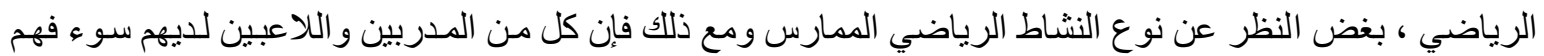

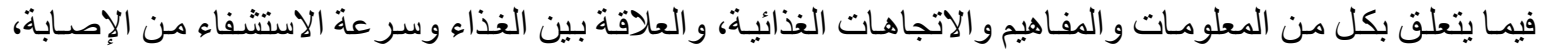

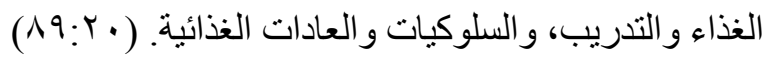

و على الر غم من تأكيد الدر اسات النظرية على أهمية التخذية لإرتباطها الوثيق بـالنو احى الحركية و البدنية و الفسيولوجية

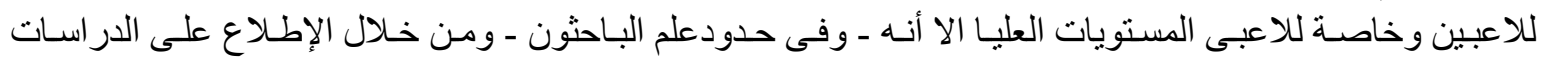

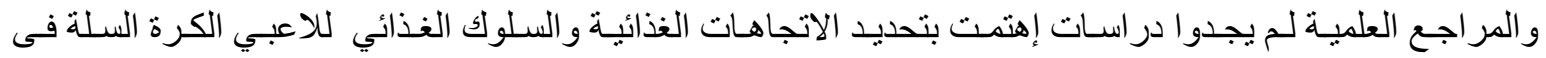

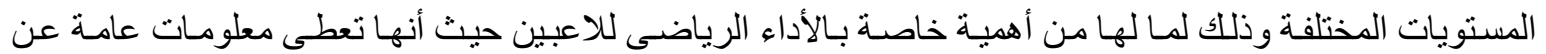
الامكانات الحركية للاعبين ، ومن هذا المنطلق فقد فكر الباحثون في دراسة الاتجاهات الغذائية والسلوك الغذائي الغئ للاعبي

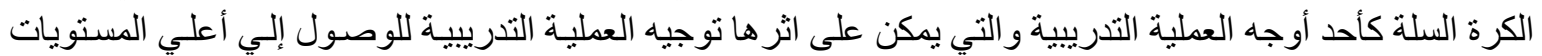

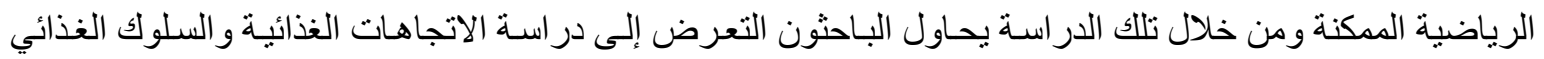
و التى لها دور فعال في توجيه عمليات التدريب وذلك كمؤشر هام وحيوى يساعد في الارثقاء بالعملية التدريبية أهداف البحث :

يهذف البحث إلى دراسة الإتجاهات الغذائية والسلوك الغذائي للاعبي كرة السلة بالدورى الممتازوذلك من خلال :

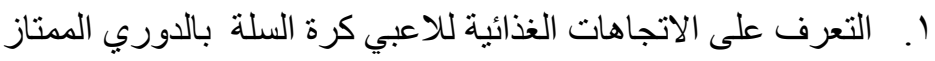

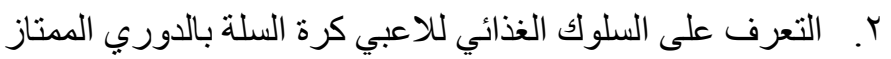
r. . التعرف على العلاقة بين الاتجاهات الغذائية والسلوك الغذائي للاعبى كرة السلة بالدوري الممتاز . فروض البحث : ا. . توجد فروق ذات دلالة إحصائية في الاتجاهات الغذائية بين لاعبي كرة السلة بالدوري الممتاز.

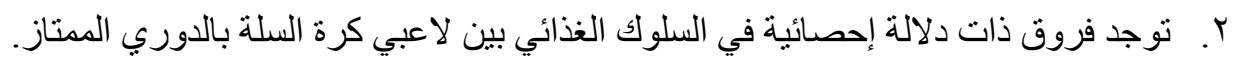
r. توجد علاقة ارتباط بين الاتجاهات الغذائية والسلوك الغذائي للاعبي كرة السلة بالدوري الممتاز

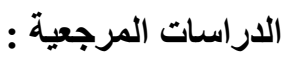

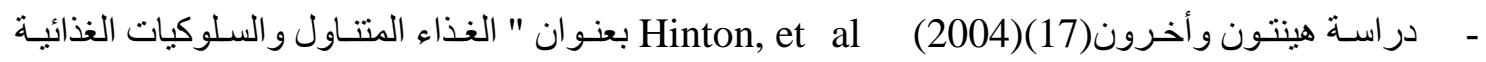

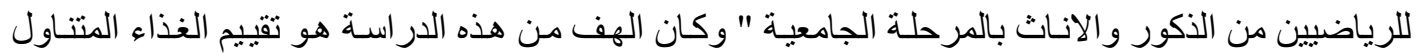

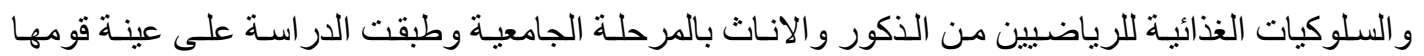

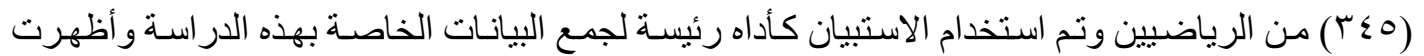

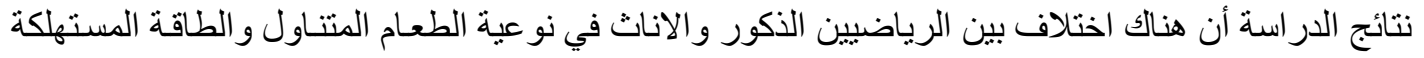

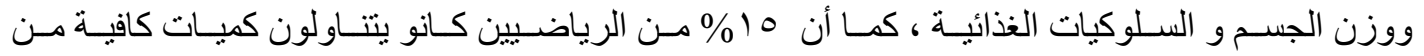

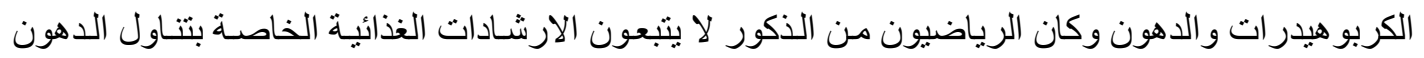


المشبعة و الكوليسترول و الصوديوم مقارنـة بالانـاث وكان بآ\% من الانـاث لديهم الرغبة في انقاص الوزن

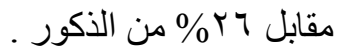

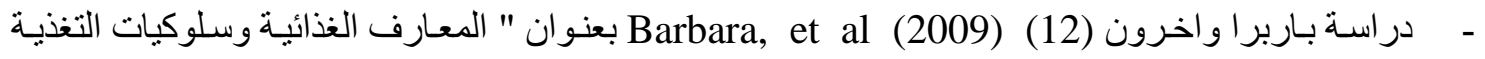

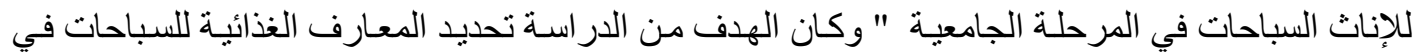

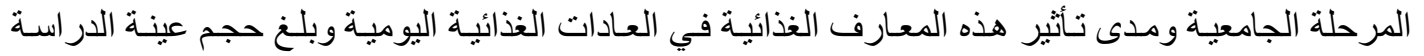

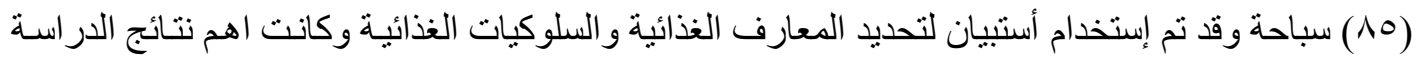

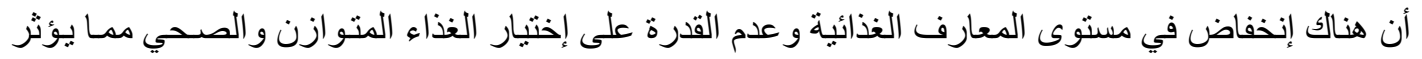
على مستوى الاداء لديهن.

در اسـة دانيشفار وأخرون(15) Daneshvar, et al (2013) بعنوان " السلوكيات الغذائية وتقيـيم التغذيـة

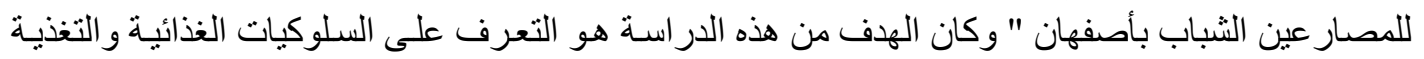

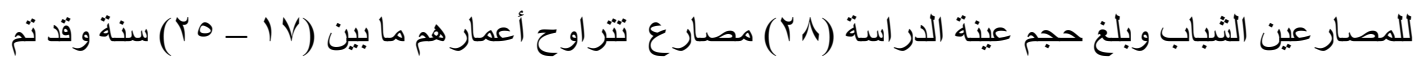

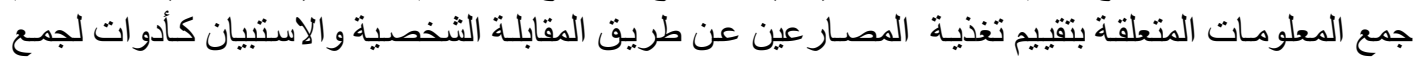

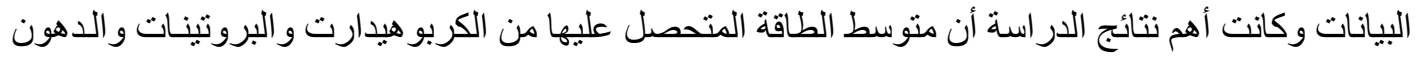

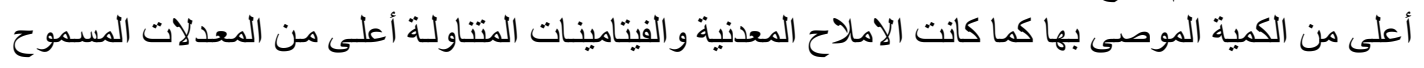

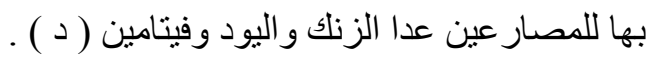

التعليق على الاراسات المرجعية :

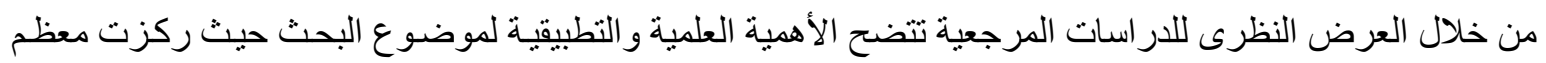

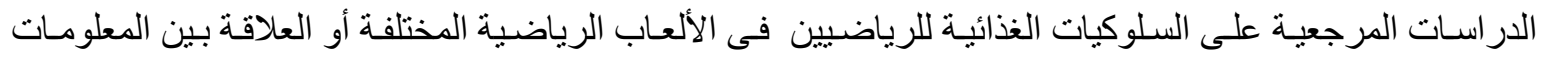

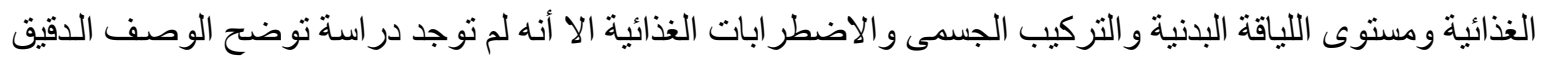

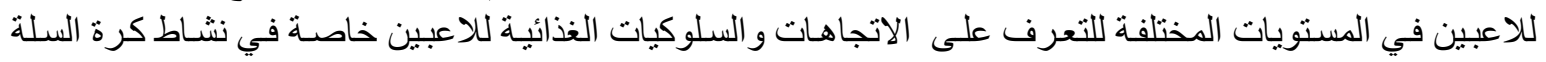

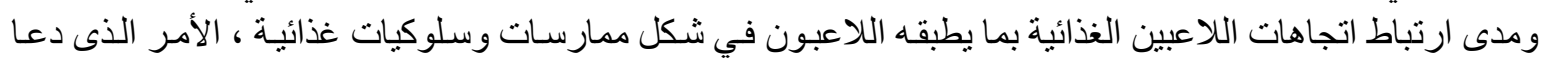

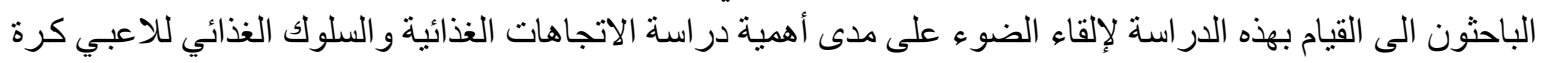

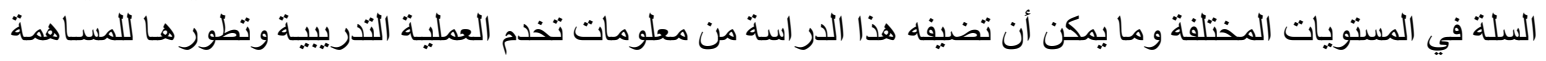
في الوصول إلى المستويات العليا.

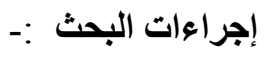
منهج البحث :إستخدم الباحثون المنهج الوصفي وذلك لملائمته لطبيعة وأهداف البحث. .

$$
\text { - - مجالات البحث : - }
$$

تم تطبيق الدر اسة بالصالة المغطاة بالمركز الاوليمبى العسكري بمدينة الإسكندرية .

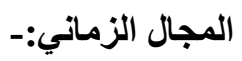

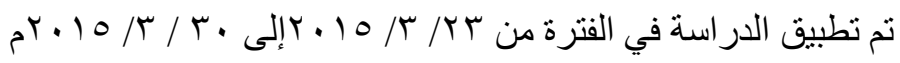
عينة البحث:-

تم إختيـار عينـة البحث مـن لاعبـي كرة السـلة مـن الفرق المشــاركة فى الدورة المجمعـة التى أقيمت بالصـالة المغطساة

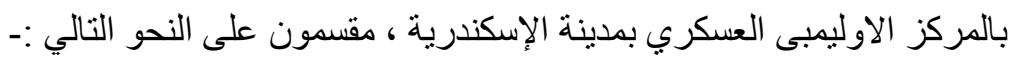

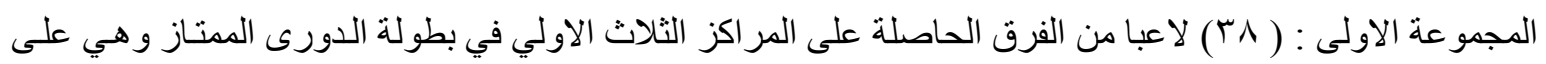
الترتيب ( سبورتتج - الجزيرة - الاتحاد السكندري) 


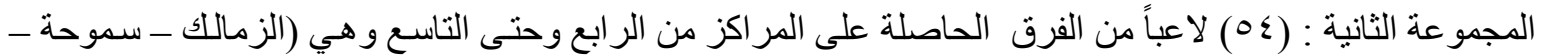
الجيش- طنطا - الثمس - الاوليمبي ) و الجدول التالي يوضح الألة الاندية وعدد اللاعبين بكل نادى .

جدول (1)

الاندية و عدد اللاعبين بكل نادى

\begin{tabular}{|c|c|c|c|}
\hline النسبة المئوية & عدد اللاعبين & اسم النادى & 5 \\
\hline$\% ! \leqslant .1 T$ & 14 & سبورتتج & 1 \\
\hline$\% 1 \pi$ & Ir & الجزيرة & $r$ \\
\hline$\% 1 \leq .1 T$ & 14 & الاتحاد السكندري & $r$ \\
\hline$\% \vee\urcorner$. & V & الزمالك & $\varepsilon$ \\
\hline$\% 1 \cdot . \wedge 7$ & 1. & سموحة & 0 \\
\hline$\% 14$ & Ir & الجيش & 7 \\
\hline$\% \%^{9} . \vee \wedge$ & 9 & طنطا & $\mathrm{V}$ \\
\hline$\% \wedge .79$ & 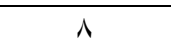 & الثمس & $\wedge$ \\
\hline$\% \wedge .79$ & $\wedge$ & الاوليمبي & 9 \\
\hline$\% 1 \ldots$ & 94 & المجموع & \\
\hline
\end{tabular}

أدوات جمع البيانات : -

استخدم الباحثون الإسنبيان مرفق ( ) كأداة رئيسية لجمع البيانات و المعلومات و التي يمكن من خلالها معرفة الاتجاهـات

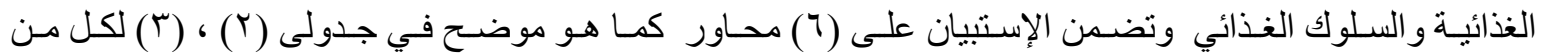

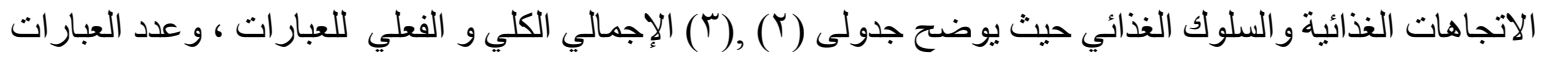
الايجابية والسلبية و العبار ات المحذوفة بكل محور من محاور الاتجاهات الغذائية و السلوك الغذائي.

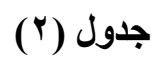

يوضح العبارات الايجابية والسلبية والعبار ات المحذوفة والإجمالي الكلي و الفعل بكل محور من محاور الاتجاهات الغذائية

\begin{tabular}{|c|c|c|c|c|c|c|}
\hline \multicolumn{5}{|c|}{ عدد العبارات } & \multirow[b]{2}{*}{ 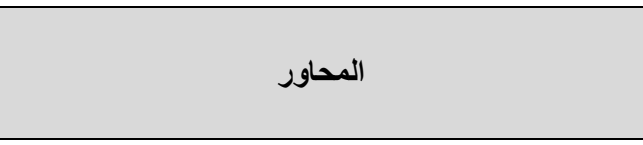 } & \multirow[b]{2}{*}{ s } \\
\hline الإجمالي & الاجمالي - الكلي & 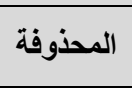 & السلبية & الايجابية & & \\
\hline $1 \leqslant$ & IV & $r$ & 9 & 0 & الاتجاهات الخاصة بالمفاهيم العامة للتغذية & 1 \\
\hline $1 \leqslant$ & 10 & 1 & $\mathrm{~V}$ & $\mathrm{~V}$ & الاتجاهات الخاصة بالعناصر الغذائية & $r$ \\
\hline 1. & Ir & r & 0 & 0 & الاتجاهات الخاصة بتخطيط الوجبات الغذائية للرياضيين & $r$ \\
\hline $1 \cdot$ & 1. & · & r & $\wedge$ & الاتجاهات الخاصة بالغذاء المتوازن والاحتياجات الغذائية & $\varepsilon$ \\
\hline$\wedge$ & 1. & r & $r$ & 0 & الاتجاهات الخاصة بالمكملات الغذائية & 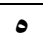 \\
\hline 0 & $\checkmark$ & r & 0 & $\cdot$ & الاتجاهات الخاصة بالتظذيةّة لإستعادة الثفاء بعد المجهود & 9 \\
\hline 71 & (1) & $1 \cdot$ & r & $r \cdot$ & الإجمالي & \\
\hline
\end{tabular}




\section{جدول (广)}

يوضح العبارات الايجابية والسلبية والعبارات المحذوفة والإجمالي الكلي و الفعلي بكل محور من محاور السلوك الغذائي

\begin{tabular}{|c|c|c|c|c|c|c|}
\hline \multicolumn{5}{|c|}{ عدد العبارات } & \multirow[b]{2}{*}{ 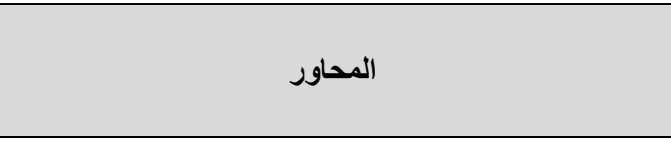 } & \multirow[b]{2}{*}{ s } \\
\hline الإجمالي & الاجلي & 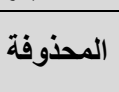 & السلبية & الايجابية & & \\
\hline 10 & 17 & 1 & 7 & 9 & السلوك الخاص بالمفاهيم العامة للتظذية & 1 \\
\hline $1 \varepsilon$ & $1 \varepsilon$ & . & $r$ & ir & السلوك الخاص بالعناصر الغذائية & r \\
\hline 1. & 11 & 1 & r & v & السلوك الخاص بتخطيط الوجبات الغذائية للرياضيين & $r$ \\
\hline $1 \cdot$ & ir & r & · & $1 \cdot$ & السلوك الخاص بالغذاء المتوازن والاحتياجات الغذائية & $\varepsilon$ \\
\hline 9 & 11 & r & r & $\mathrm{v}$ & السلوك الخاص بالمكملات الغذائية & 0 \\
\hline $\mathrm{v}$ & 9 & r & . & v & السلوك الخاص بالتفذية لإستعادة الثفاء بعد المجهود البدني & 7 \\
\hline 70 & $V \varepsilon$ & 9 & ir & or & الإجمالي & \\
\hline
\end{tabular}

\section{المعاملات العلمية لإستمارة الاستبيان:}

تم حساب المعاملات العلمية لإستمارة الاستبيان (الصدق - الإنماندان الثبات) .

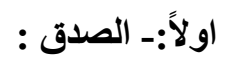

تم حساب الصدق عن طريق ( صدق المحتوى )

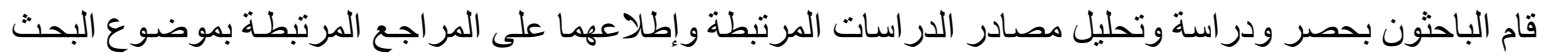

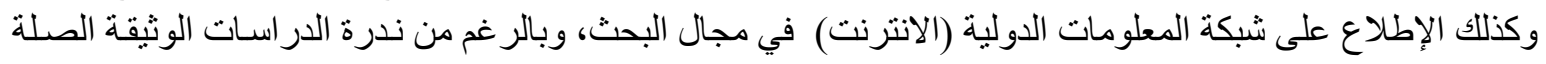

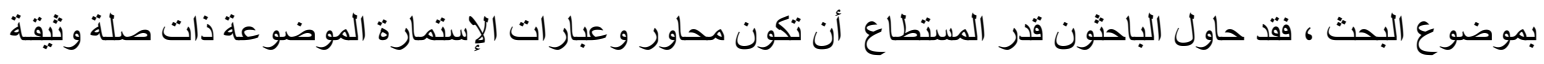

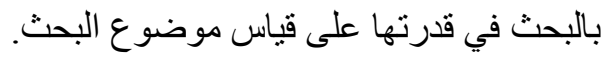
ثانياً الثبات : بالث

تم حساب الثبات عن طريق (معامل ألفالكرونباك) قام البـاحثون بحسـاب ثبـات الاستمارة عن طريق حسبـاب معامل ألفالكرونبـاك للعبـار ات الخاصـة بمحساور الاتجاهـات الغذائية و السلوك الغذائي.

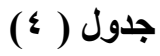

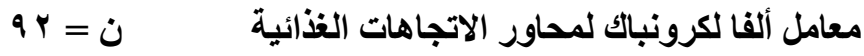

\begin{tabular}{|c|c|c|}
\hline معامل ألفا لكرونباك & 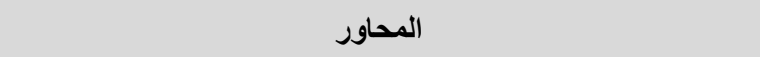 & s \\
\hline .71 & الاتجاهات الخاصة بالمفاهيم العامة للتغذية & 1 \\
\hline .79 & الاتجاهات الخاصة بالعناصر الغذائية & $r$ \\
\hline. $\mathrm{VH}$ & الاتجاهات الخاصة بتخطيط الوجبات الغذائية للرياضيين & $r$ \\
\hline$\cdot v \cdot$ & الاتجاهات الخاصة بالذذاء المتوازن والاحتياجات الغذائية للرياضيين & $\varepsilon$ \\
\hline .71 & الاتجاهات الخاصة بالمكملات الغذائية & 0 \\
\hline .79 & الاتجاهات الخاصة بالتغذية لإستعادة الثفاء بعد المجهود البدني & 7 \\
\hline
\end{tabular}

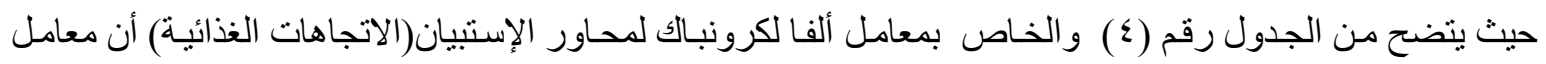

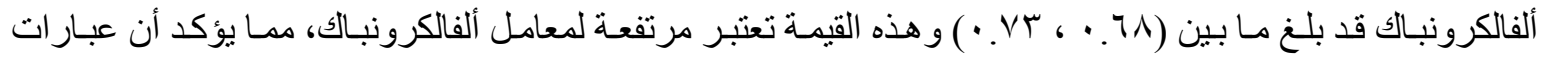

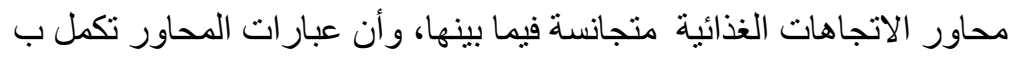
ناء المحاور ذاتها، وأن أي حذف أو أي إضافة لأي عبارة في المحاور من الممكن أن بؤثر سلبيا في بناء المحاور ذاتها. 
جدول (0)

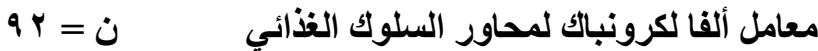

\begin{tabular}{|c|c|c|}
\hline معامل ألفا لكرونباك & المحاور & r \\
\hline .79 & السلوك الخاص بالمفاهيم العامة للتغذية & 1 \\
\hline $.7 \mathrm{~V}$ & السلوك الخاص بالعناصر الغذائية & r \\
\hline$\because V V$ & السلوك الخاص بتخطيط الوجبات الغذائية للرياضيين & $r$ \\
\hline$\because \mathrm{V}$ & السلوك الخاص بالغذاء المتوازن والاحتياجات الغذائية للرياضيين & $\varepsilon$ \\
\hline .71 & السلوك الخاص بالمكملات الغذائية & $\bullet$ \\
\hline .70 & السلوك الخاص بالتغذية لإستعادة الشفاء بعد المجهود البذني & 7 \\
\hline
\end{tabular}

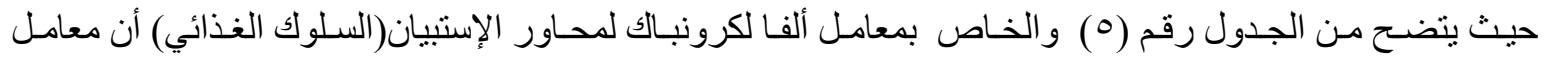

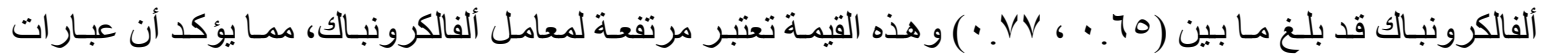

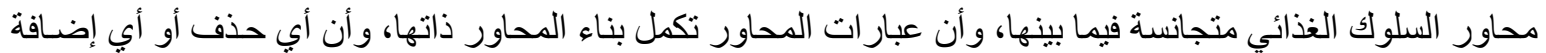

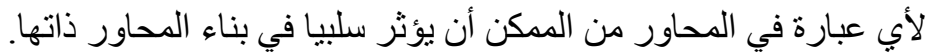

إعتدالية توزيع المتغيرات ( البيانات )

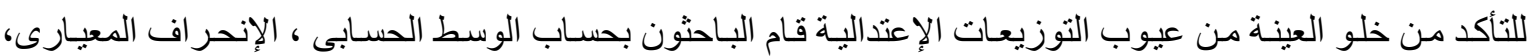

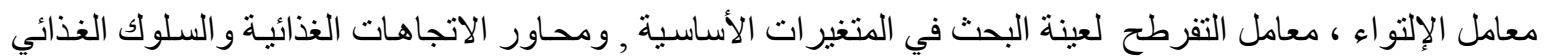
قيد البحث وهى على النحو التالى :-

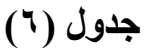

الالالات الإحصائية للمتغيرات الأساسية لعينة البحث

\begin{tabular}{|c|c|c|c|c|c|c|c|c|}
\hline التفرطح & الإلتواء معامل & المعياري & الحسابي & أكبر قيمة & أقل قيمة & والقياس & ت الإحصائية & \\
\hline 0.33 & 0.75 & 4.98 & 26.79 & 41.00 & 19.00 & سنة & السن & \multirow{4}{*}{ 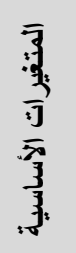 } \\
\hline $0.332-$ & 0.06 & 9.24 & 194.05 & 215.00 & 171.00 & سم & الطول & \\
\hline $0.392-$ & 0.16 & 12.28 & 92.26 & 120.00 & 60.00 & كجم & الوزن & \\
\hline 1.02 & $0.219-$ & 1.96 & 24.42 & 30.47 & 18.11 & كجم/2' & B M I & \\
\hline
\end{tabular}

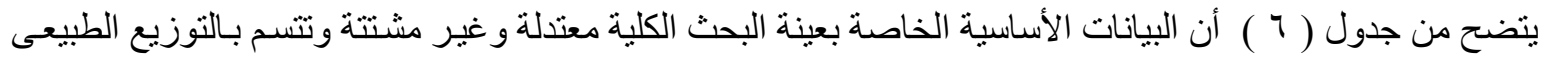

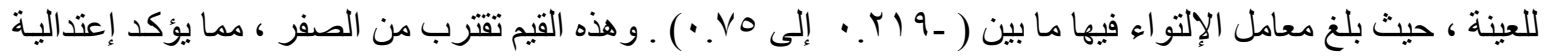
البيانات الخاصة بالمتغير ات الأساسية.

(V) جدول

الوسط الحسابي والإنحراف المعيارى ومعامل الالتواء والتفرطح لعينة البحث في محاور الإتجاهات الغذائية $q r=\dot{0}$

\begin{tabular}{|c|c|c|c|c|c|c|c|}
\hline التفرطح & الإلتواء & المعياري & الحسابي & أكبر قيمة & أقل قيمة & الدلالات الإحصائية & r \\
\hline 8.05 & 2.14 & 2.71 & 22.16 & 34.00 & 17.00 & الاتجاهات الخاصة بالمفاهيم العامة للتظذية & 1 \\
\hline-0.53 & -0.28 & 2.06 & 22.70 & 27.00 & 18.00 & الاتجاهات الخاصة بالعناصر الغذائية & r \\
\hline-0.18 & 0.20 & 1.58 & 15.66 & 20.00 & 12.00 & الاتجاهات الخاصة بتخطيط الوجبات الغذائية & $r$ \\
\hline 0.07 & -0.73 & 1.85 & 17.20 & 20.00 & 12.00 & الاتجاهات الخاصة بالغذاء المتوازن & $\varepsilon$ \\
\hline
\end{tabular}




\begin{tabular}{|c|c|c|c|c|c|c|c|}
\hline التفرطح & الإلتواء معامل & المعياري & الوسابي & أكبر قيمة & أقل قيمة & المحاور الدلالات الإحصائية & p \\
\hline & & & & & & والاحتياجات الغذائية للرياضيين & \\
\hline-0.51 & -0.32 & 1.66 & 12.93 & 16.00 & 9.00 & الاتجاهات الخاصة بالمكملات الغذائية & 0 \\
\hline-0.57 & 0.26 & 1.28 & 7.53 & 10.00 & 5.00 & الاتجاهات الخاصة بالتخذية لإستعادة الثفاء البذاء & 7 \\
\hline-0.56 & -0.04 & 6.18 & 98.18 & 111.00 & 83.00 & المجموع & \\
\hline
\end{tabular}

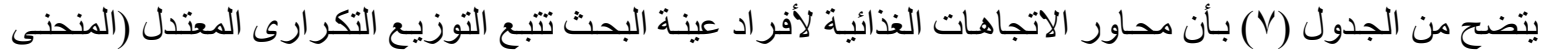

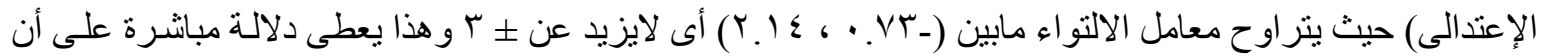

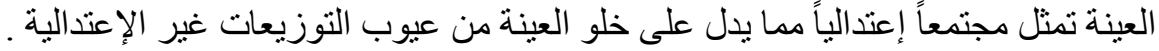

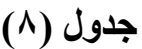

الوسط الحسابي والإنحراف المعيارى ومعامل الالتواء والتفرطح لعينة البحث في محاور السلوك الغذائي $q r=\dot{0}$

\begin{tabular}{|c|c|c|c|c|c|c|c|}
\hline التفرطح & المعامل الإلتواء & المعياري & الصسابي & قأكبر & أقل قيمة & ل الالالات الإحصائية & p \\
\hline-0.28 & 0.09 & 2.01 & 22.01 & 27.00 & 18.00 & السلوك الخاص بالمفاهيم العامة للتذذية & 1 \\
\hline-0.34 & -0.03 & 2.08 & 23.42 & 28.00 & 18.0 & السلوك الخاص بالعناصر الغذائية & $r$ \\
\hline-0.61 & 0.06 & 1.60 & 15.74 & 19.00 & 12.00 & السلوك الخاص بتخطيط الوجبات الغذائية & $r$ \\
\hline-0.09 & -0.35 & 1.92 & 17.29 & 20.00 & 11.00 & السلوك الخاص بالغذاء المتوازن والاحتياجين للغيات & $\varepsilon$ \\
\hline-0.68 & -0.33 & 1.83 & 14.64 & 18.00 & 11.00 & السلوك الخاص بالمكملات الغذائية & $\bullet$ \\
\hline 1.15 & -0.68 & 1.31 & 11.75 & 14.00 & 7.00 & 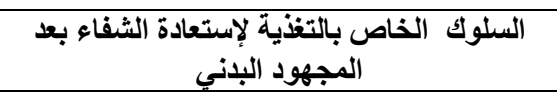 & 7 \\
\hline-0.05 & -0.15 & 6.39 & 104.86 & 119.00 & 85.00 & المجموع & \\
\hline
\end{tabular}

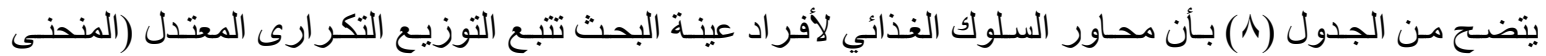

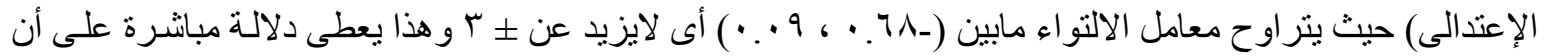

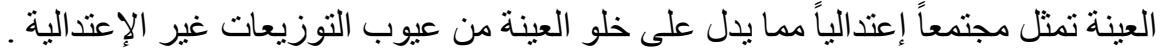
الار اسة الأساسية : الاسية

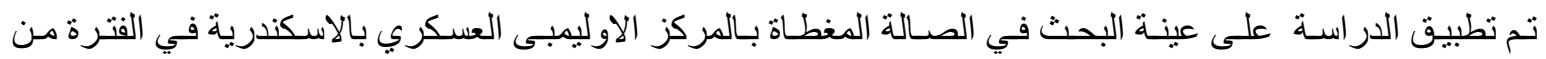

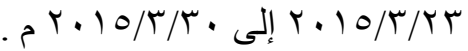

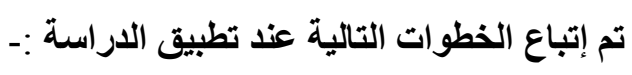
- قام الباحثون بأخذ موافقة من الأجهزة الفنبة والادارية للفرق المشاركة في الدورة المجمعة لتطبيق البحث على الناعبين

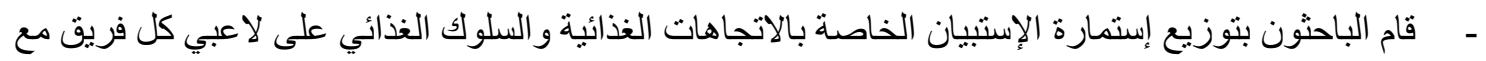

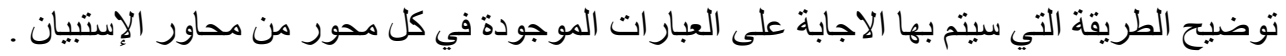
- - قام الباحثون بتجميع إستمار ات الإستبيان من اللاعبين في الايام النالية لتوزيع الاستمارة . - قام الباحثون بتفريغ جميع إستمار ات الإستبيان و اجر اء المعالجات الاحصائية لاستخر اج النتائج .

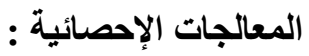
قام الباحثون بإستخدام المعالجات الإحصائية لتحقيق أهداف البحث وفروضنه وهى كالتالى :

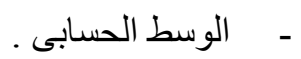




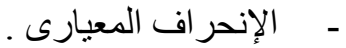

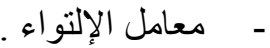

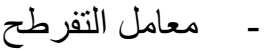

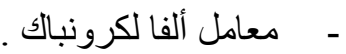

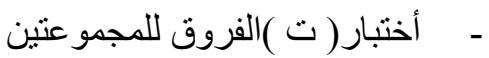

- معامل الارتباط البسيط لبيرسون

عرض النتائج ومناقشتها :-

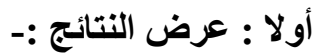

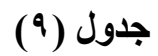

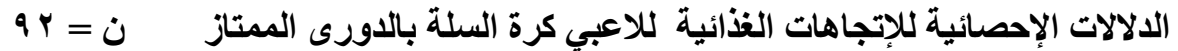

\begin{tabular}{|c|c|c|c|c|c|c|c|}
\hline \multirow{2}{*}{ 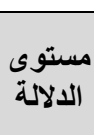 } & \multirow{2}{*}{ قيمة } & \multirow{2}{*}{ المتوسطين } & \multicolumn{2}{|c|}{ الن=وعة الثانية } & \multicolumn{2}{|c|}{ 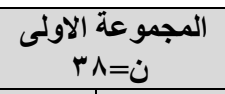 } & \multirow{2}{*}{ المحاور الدالات الإحصانية } \\
\hline & & & $\varepsilon^{ \pm}$ & سن & $\varepsilon_{ \pm}$ & سن & \\
\hline 0.79 & 0.26 & 0.17 & 3.03 & 22.21 & 1.65 & 22.04 & الاتجاهات الخاصة بالمفاهيم العامة للتغذية \\
\hline 0.01 & 2.66 & 1.24 & 2.04 & 22.36 & 1.87 & 23.60 & الاتجاهات الخاصة بالعناصر الغذائية \\
\hline 0.00 & 3.01 & 1.07 & 1.45 & 15.37 & 1.66 & 16.44 & الاتجاهات الخاصة بتخطيط الوجبات الغذائية \\
\hline 0.00 & 3.06 & 1.27 & 1.91 & 16.85 & 1.30 & 18.12 & الاتجاهات الخاصذة بالغذاء المتوازن والاحتياجيات \\
\hline 0.61 & 0.51 & 0.20 & 1.64 & 12.88 & 1.75 & 13.08 & الاتجاهات الخاصة بالمكملات الغذائية \\
\hline 0.30 & 1.04 & 0.31 & 1.12 & 7.45 & 1.64 & 7.76 & الاتجاهات الخاصة بالتظذية لإستعادة الثنفاء بعد \\
\hline 0.01 & 2.81 & 3.92 & 6.11 & 97.12 & 5.53 & 101.04 & مجموع محاور الاتجاهات الغذائية \\
\hline
\end{tabular}

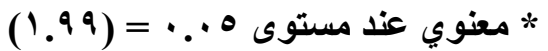

يتضح من الجدول رقم ( 9 ) الخاص بالدلالات الإحصائية لمحاور الاتجاهات الغذائية بين المجموعتين فى الاتجاهات الغذائية قيد البحث.

وجود فروق ذات دلالة إحصائية عند مستوى (0 . . ) فى بعض محاور الاتجاهـات الغذائية لصسالح لاعبي كرة السلة

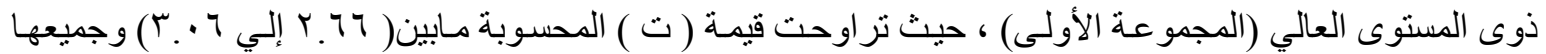

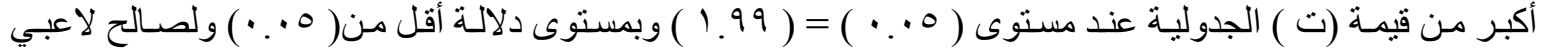
المستوى العالي فى بعض محاور الاتجاهات الغذائية .

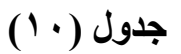

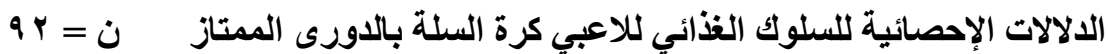

\begin{tabular}{|c|c|c|c|c|c|c|c|}
\hline \multirow{2}{*}{ 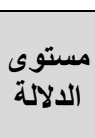 } & \multirow{2}{*}{ قيمة } & \multirow{2}{*}{ الفرق بين } & \multicolumn{2}{|c|}{ المجوعة الثانية } & \multicolumn{2}{|c|}{ 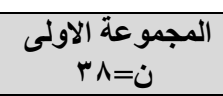 } & \multirow{2}{*}{ المحاور الدالات الإحصائية } \\
\hline & & & $\varepsilon^{ \pm}$ & سن & $\varepsilon^{ \pm}$ & سن & \\
\hline 0.01 & 2.74 & 1.25 & 2.08 & 21.67 & 1.53 & 22.92 & السلوك الخاص بالمفاهيم العامة للتظذية \\
\hline 0.01 & 2.85 & 1.34 & 1.97 & 23.06 & 2.10 & 24.40 & السلوك الخاص بالعناصر الغذائية \\
\hline 0.02 & 2.33 & 0.85 & 1.47 & 15.51 & 1.78 & 16.36 & السلوك الخاص بتخطيط الوجبات الغذائية للرياضيين \\
\hline 0.01 & 2.74 & 1.19 & 1.83 & 16.97 & 1.93 & 18.16 & السلوك الخاص بالغذاء المتوازن والاحتياجات \\
\hline 0.53 & 0.63 & 0.27 & 1.79 & 14.57 & 1.95 & 14.84 & السلوك الخاص بالمكملات الغذائية \\
\hline
\end{tabular}




\begin{tabular}{|c|c|c|c|c|c|c|c|}
\hline \multirow{2}{*}{ مستوى } & \multirow{2}{*}{ قيمة } & \multirow{2}{*}{ المترق بين } & \multicolumn{2}{|c|}{ المجوعة الثاتية } & \multicolumn{2}{|c|}{ 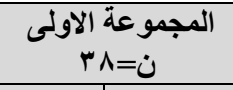 } & \multirow[t]{2}{*}{ الالالات الإحصائية } \\
\hline & & & $\varepsilon^{ \pm}$ & 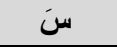 & $\varepsilon^{ \pm}$ & سن & \\
\hline 0.03 & 2.23 & 0.67 & 1.31 & 11.57 & 1.23 & 12.24 & السلوك الخاص بالتغذية لإستعادة الشفاء بعد المجني \\
\hline 0.00 & 4.02 & 5.58 & 5.96 & 103.34 & 5.81 & 108.92 & مجموع محاور السلوك الغذائي \\
\hline
\end{tabular}

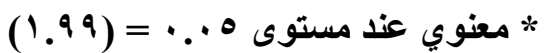

يتضح من الجدول رقم ( • ( ) و الخاص بالدلالات الإحصـائية لمحاور السلوك الغذائي بين المجمو عتين في السلوك الغذائي :

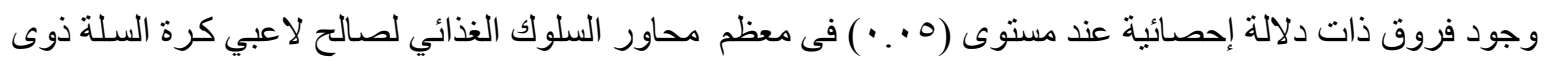

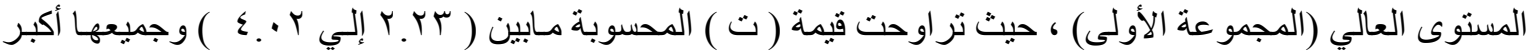

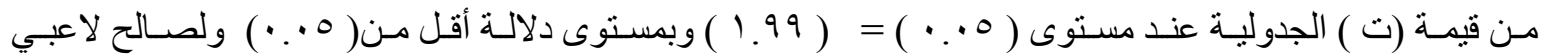

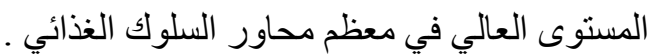

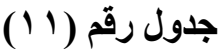

معامل الارتباط بين محاور الاتجاهات الغذائية والسلوك الغذائي للاعبي كرة السلة بالدورى الممتاز

\begin{tabular}{|c|c|c|c|c|c|c|c|}
\hline مجموع السذوك & 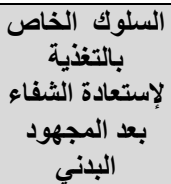 & 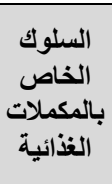 & 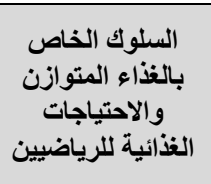 & التذائية للرياضيبين الوباص & الخاصناص الغنائية & 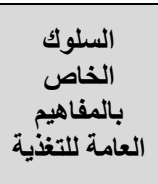 & المحاور \\
\hline 0.20 & 0.03 & 0.06 & $0.227^{*}$ & $0.220^{*}$ & 0.12 & 0.03 & 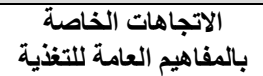 \\
\hline $0.339^{* * *}$ & $0.240^{*}$ & $0.213^{*}$ & $0.276^{* *}$ & 0.11 & $0.315^{* *}$ & 0.05 & بالاتجاصرات الخذاصية \\
\hline $0.321^{* *}$ & $0.208^{*}$ & 0.14 & 0.19 & $0.336^{* *}$ & $0.241^{*}$ & 0.06 & بتخطيط الوجبات الغذائية \\
\hline $0.515^{* *}$ & $0.296^{* * *}$ & 0.16 & $0.545^{* *}$ & $0.256^{*}$ & $0.387^{* *}$ & 0.18 & 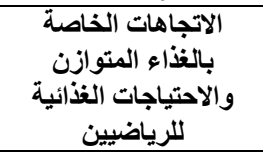 \\
\hline $0.396^{* *}$ & $0.289^{* *}$ & 0.20 & $0.295^{* *}$ & $0.288^{* * *}$ & 0.20 & 0.17 & بالاتجماهات الذذائية \\
\hline 0.17 & 0.10 & 0.03 & 0.10 & $0.214^{*}$ & 0.17 & 0.01 & 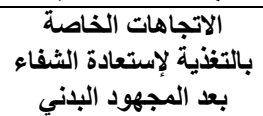 \\
\hline $0.576^{* *}$ & $0.334^{* *}$ & $0.239^{*}$ & $0.502^{* *}$ & $0.417^{* *}$ & $0.425^{* *}$ & 0.15 & مجموع محاور الاتجاهات \\
\hline
\end{tabular}

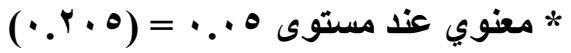

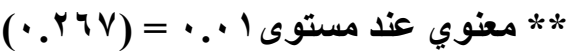

يتضح من الجدول رقم (1 1 ( ) وجود علاقة ارتباط بين بعض محاور الإتجاهات الغذائية ومحاور السلوك الغذائي للاعبي

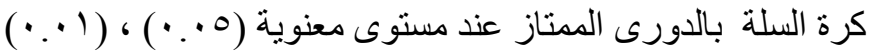

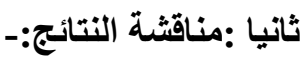

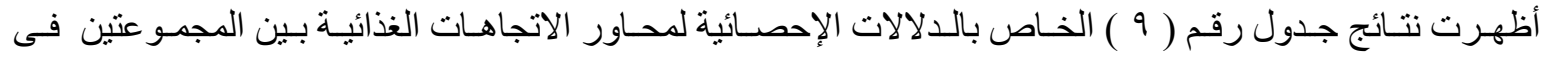

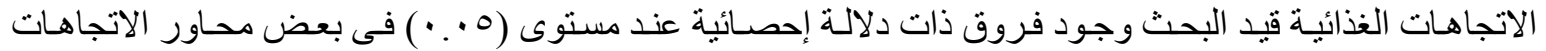

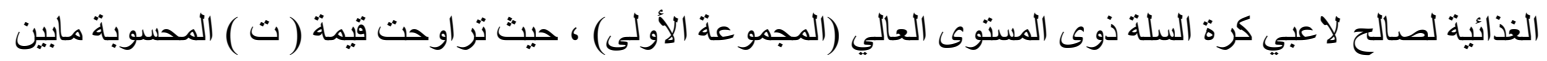




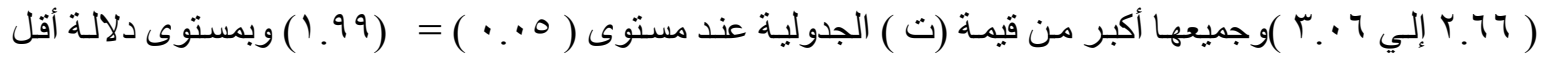

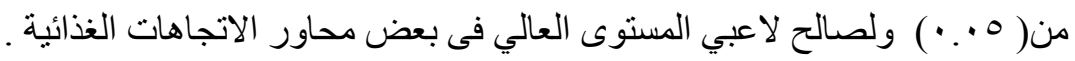

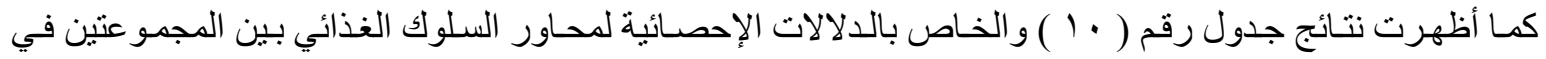

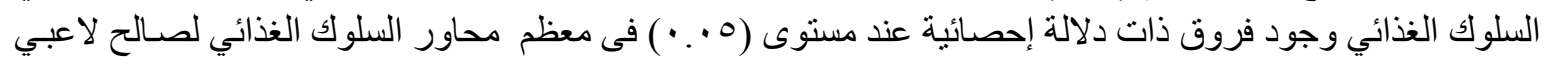

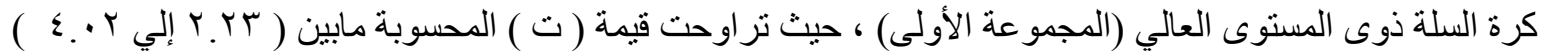

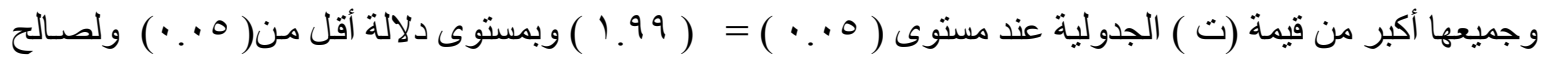
لاعبي المستوى العالي في معظم محاور السلوك الته الغذائي. ويرجع الباحثون أن هذا التفوق لدى لاعبي المستوى العالي يعزى إلى مدى جدية إهتمـام لاعبي ومدربي أنديـة الدوري

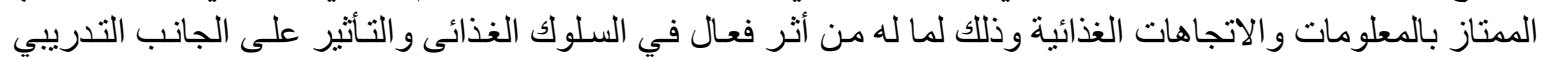

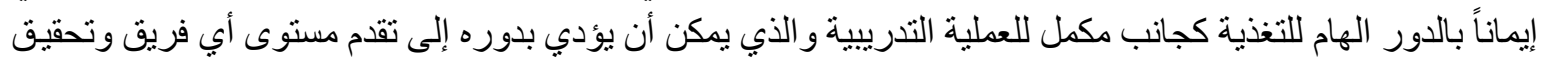

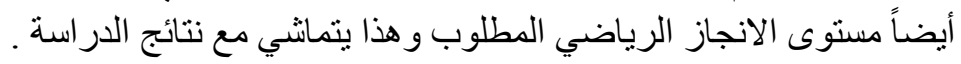

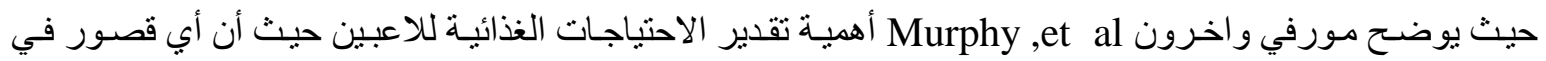

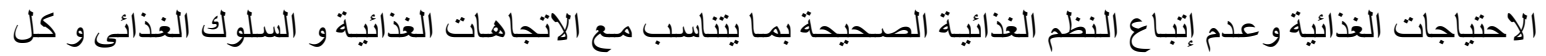

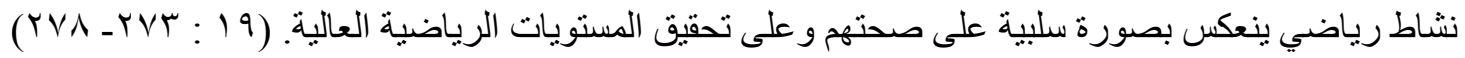

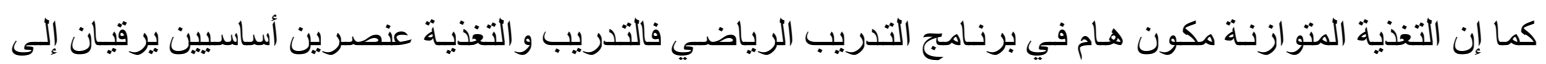

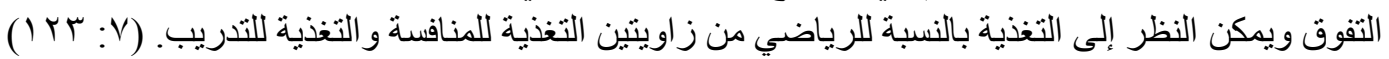

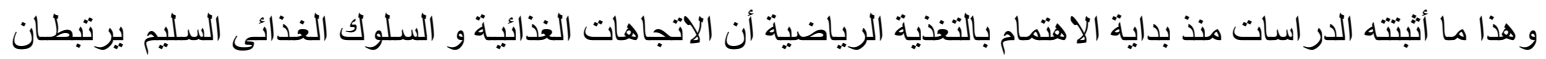

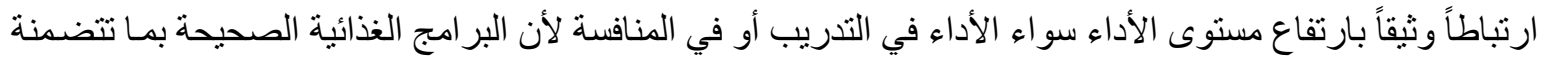

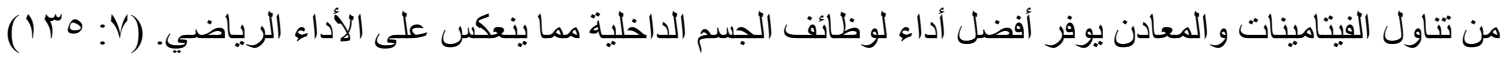

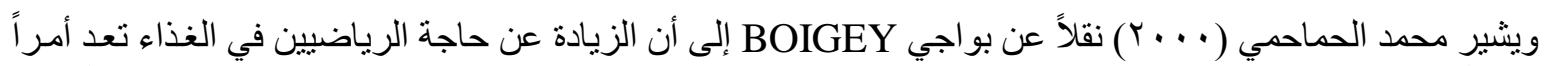

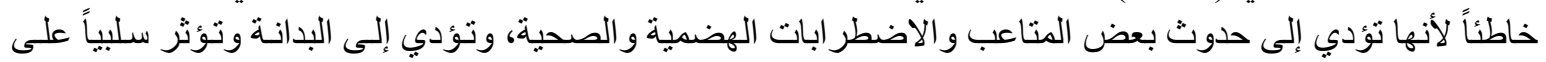

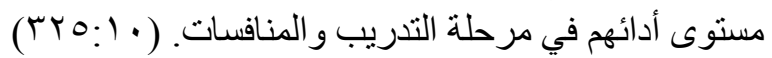

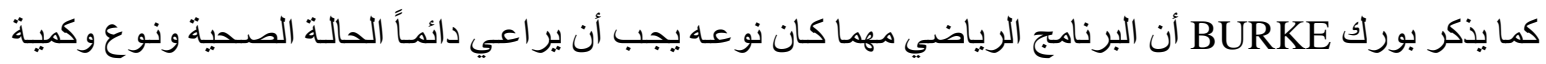

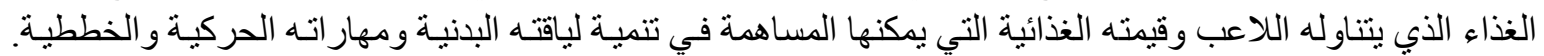

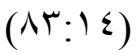

وبهذا يتحقق الفرض الأول و الثانى من فروض البحث وهو وجود فروق ذات دلالـة إحصـائية في الإتجاهـات الغذائية

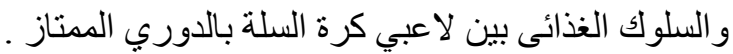
وبالنظر إلى جدول رقم (1) 1 (1) والذي يوضـح معامل الارنباط بين محاور الاتجاهـات الغذائيسة والسلوك الغذائي للاعبي

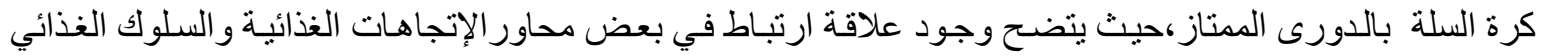

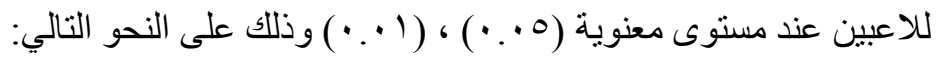
حيث يوجد علافة ارتباط إيجابى عند مستوى معنويـة ه . • بين محور الاتجاهـات الخاصـة بالمفاهيم العامـة للتغذيـة

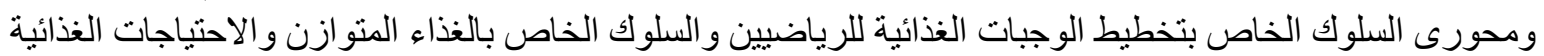
للارياضبين. كما يوجد إرتباط إيجابى أيضا عند مستوى معنوية (0 . • ) بين محور الاتجاهات الخاصة بالعناصر الغذائية ومحورى

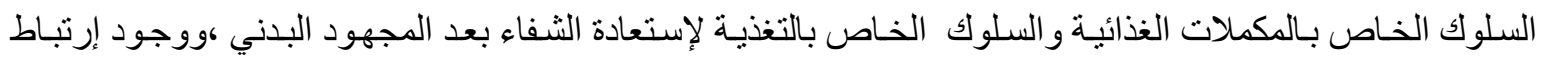

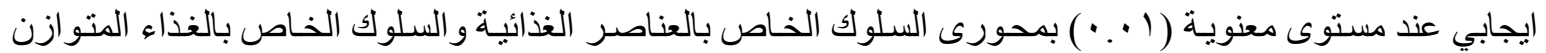
والاحتياجات الغذائية للرياضيين معنو وأيضا مجموع محاور السلوك الغذائي . 


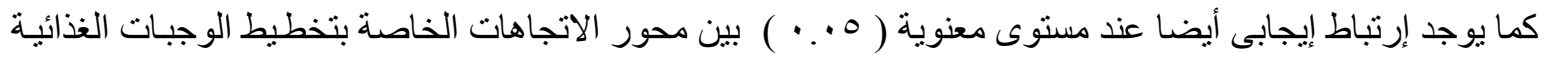

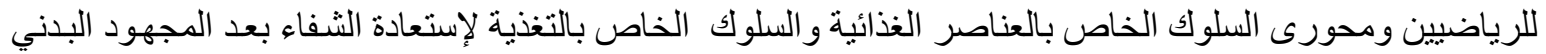

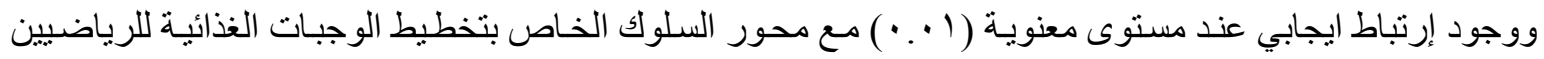
ومجموع محاور السلوك الغذائي.

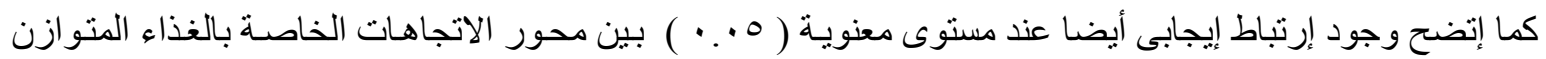

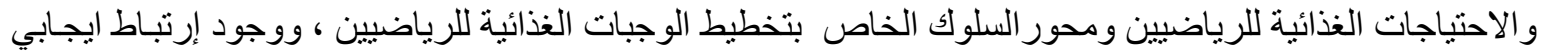

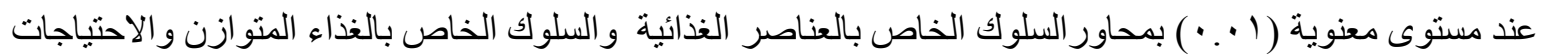

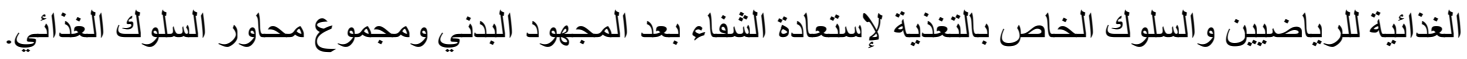

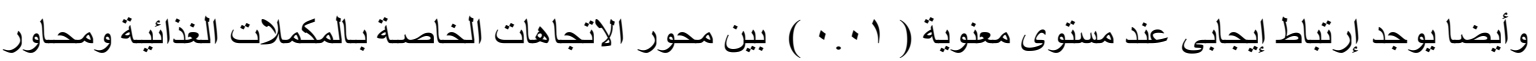

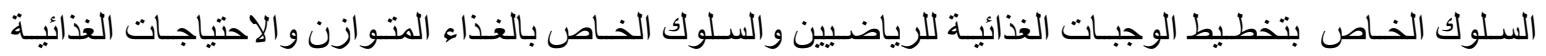

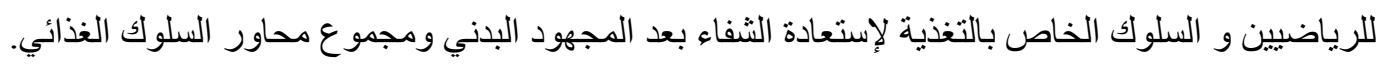

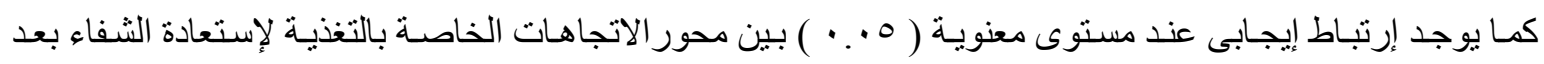

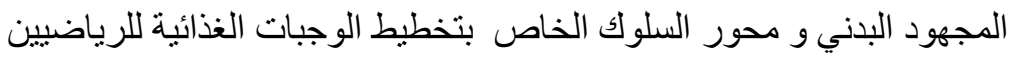

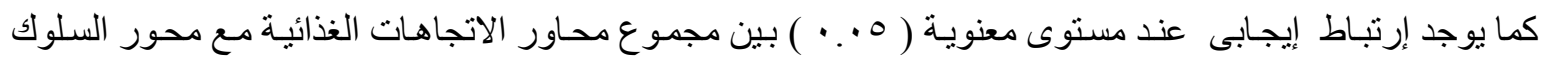

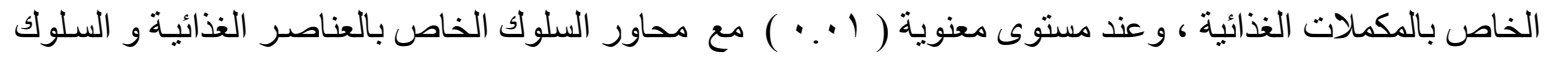

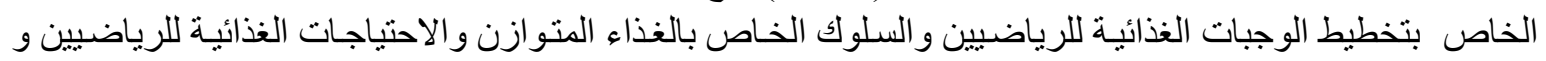

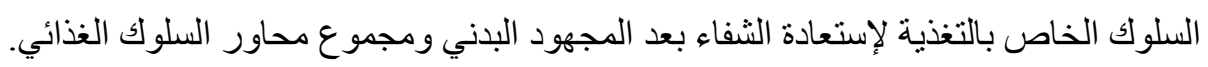

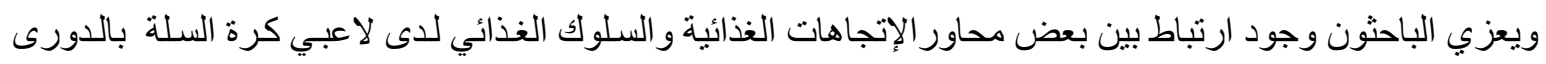

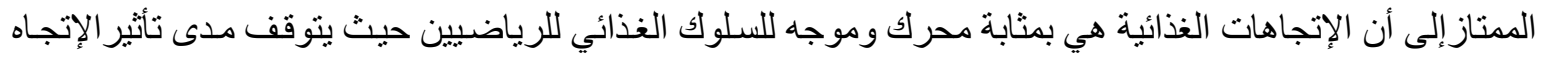

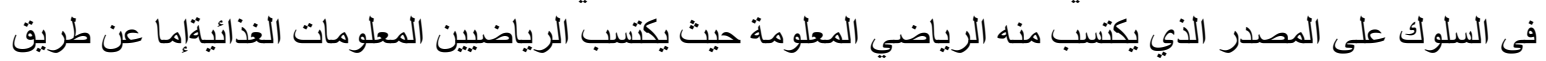

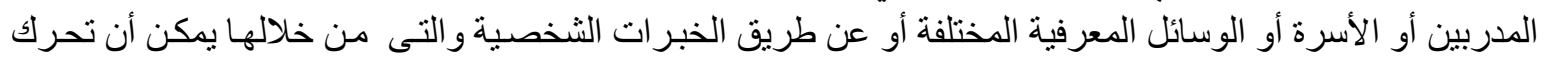

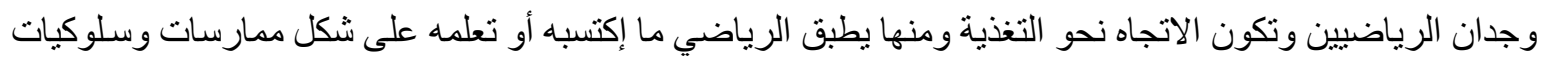
غذائية .

حيث توضح العديد من الآراء العلمية مدى أهمية الإتجاهـات الغذائية وارتباطها بالسلوك الغذائي للافر اد بصفة عامـة

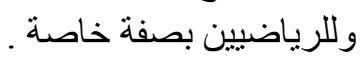

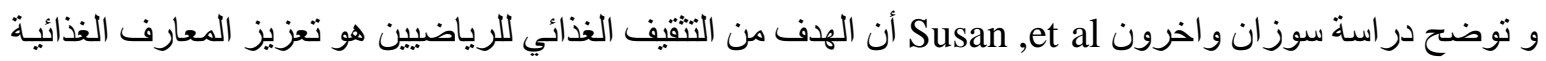

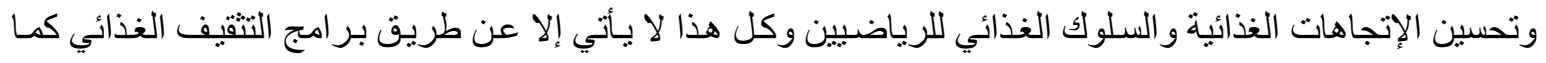

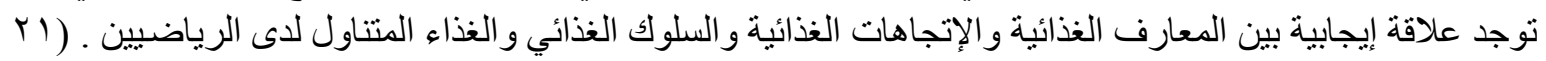
( $r \leqslant \wedge$ :

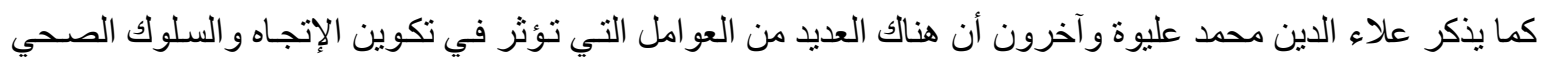

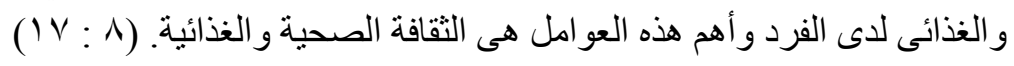

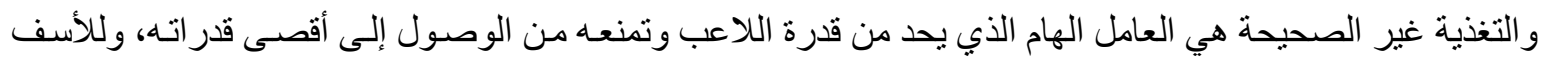

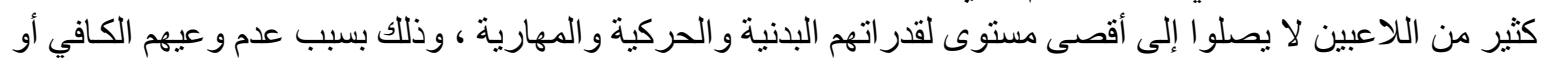

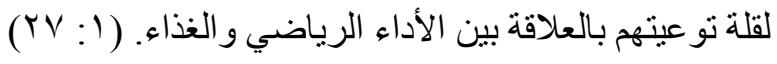

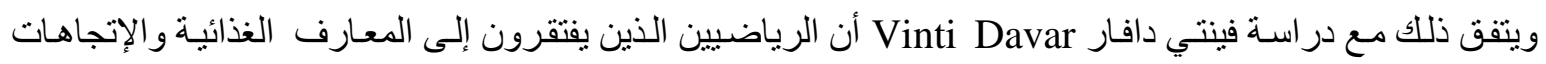

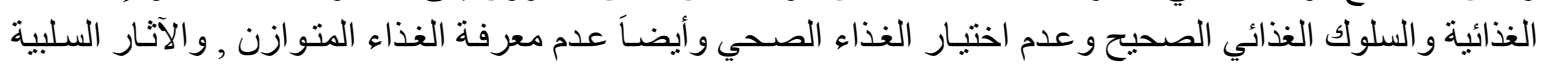

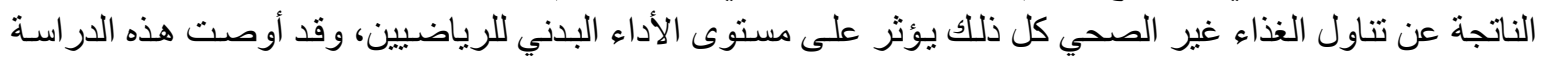


بعمل حلقات تدريبية أو مو اد تعليمية لتشجيع اكتساب المزيد من المعارف الغذائية والاتجاهات الصحية بين الرياضيين.

( $\left.1 Y \varepsilon_{-} 119: Y r\right)$

كما يذكر علاء الدين عليوة أن التغذية الصحية تعني إتباع إتجاهات غذائية وسلوك غذائي وعادات غذائيسة سليمة نتيجة

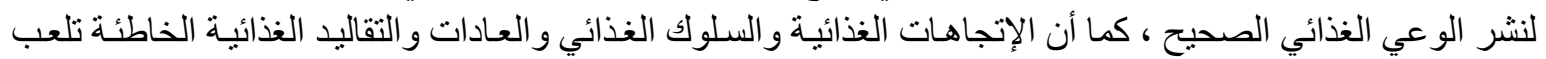

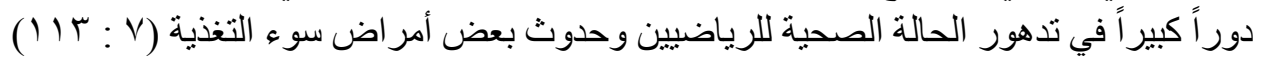

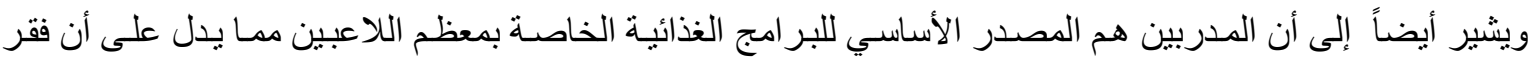

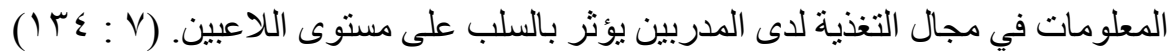
ويذكر بورك BURKE أن أهم المعارف التي يجب أن يلم بها المدرب في المجال الرياضي وخاصة التدريب الرياضي

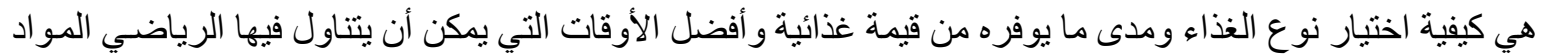

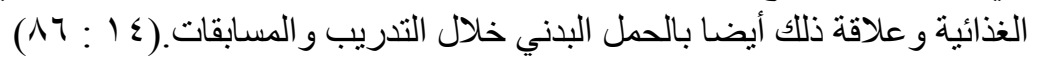
ويوضح سليمان حجر أن الإنسان وحدة بنائية متكاملة يؤثر كل جانب فيها في بـاقي الجو انب ويتأثر بها حيث أن أن الإلمام

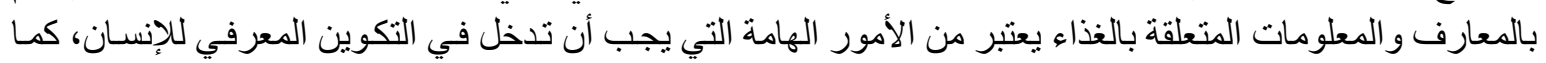

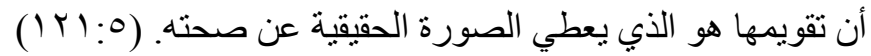
وبهذا يتحقق الفرض الثالث من البحث حيث توجد علاقة ارتباط بين الاتجاهـات الغذائيسة والسلوك الغذائي للاعبي كرة السلة بالأدوري الممتاز

الاستنتاجات :- (الات

من و اقع النتائج التي توصل إليها الباحثون وفي إطلار المعالجات الإحصسائية المستخدمة في حدود عينـة البحث أمكن

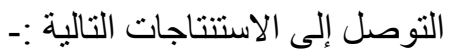

- تفوق لاعبي المستوى العـالي و الحاصلون على المر اكز الثناث الاولى بالدورى الممتـاز في بعض محاور

الإتجاهات الغذائية

- تفوق لاعبي المستوى العالي والحاصلون على المر اكز الثنلاث الاولى بالدورى الممتـاز في معظم محاور

السلوك الغذائي .

ـ وجود علاقـة ارتبـاط في بعض محساور الاتجاهـات الغذائيسة و السـوك الغذائي للاعبى كرة السـلة بالدورى الممتاز.

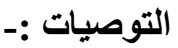

بناءاً على إستتناجات البحث وفي ضوء ما تم من إجر اءات يوصي الباحثون بما يلي :-

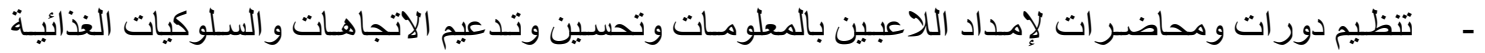

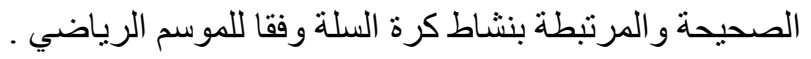
- وضع بر امج تنقيف غذائي للاعبي ومدربي كرة السلة .

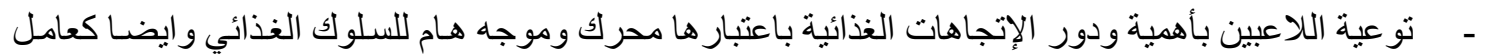
هام ومؤثر في نجاح العملية التدريبية . ـ ضرورة حث المدربين للإطلاع على ما هو جديد في مجال تغذيـة الرياضيين خـلال الموسم التدريبى و إمداد

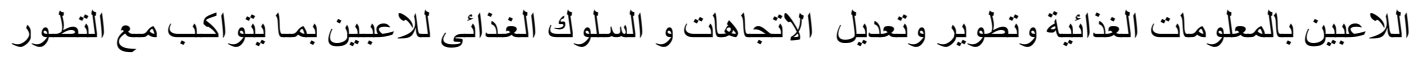

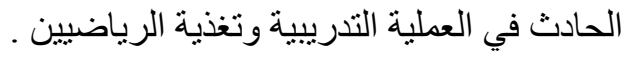
- وضـع إختبـار ات دوريـة للاعبين لتقيهم المعلومـات والاتجاهـات و السـلوكيات الغذائيـة خـلال مر احل الموسـم الرياضي . 
ـ تطبيق استبيان الاتجاهات الغذائية والسلوك الغذائي المقترح من قبل الباحثون و الذي تم استخدامه في البحث

الحالي في أنشطة رياضية أخرى.

ـ إجر اء المزيد من الدر اسات العلمية والتي تتعلق بالإتجاهات الغذائيسة و السـلوك الغذائي وتغذيـة الرياضيين في

الانشطة الرياضية الاخرى وخلال مر احل سنية مختلفة على اللاعبين و المدربين .

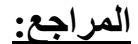

\section{أولاً :المراجع العربية:}

ا. احمد عثمان عبد الحميد احمد الدهشان :در اسة الاتجاهات الغذائية ونو عبة الوجبات وارتباطها بالوظائف المناعية والحالة الوظيفية

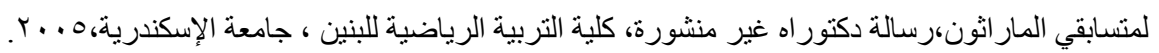

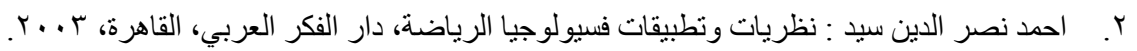

ץ. بهاء الدين إبراهيم سلامة: صحة الغذاء ووظائف الأعضاء، دار الفكر العربي، القاهرة، .......

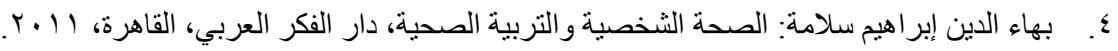

○. سليمان حجر : مقياس المعلومات الغذائية لطلبة وطلاب المرحلة الجامعية، مؤتمر الرياضة للجميع في الدول النامية، المجلد الأول،

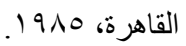

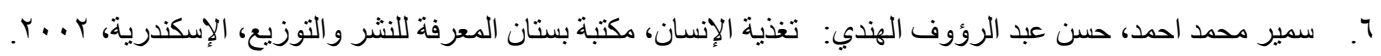

V. . علاء الدين محمد عليوة: الصحة الرياضية "منشطات ـ استعادة شفاء ـ تغذية الرياضيين"، دار الوفاء لدنيا الطباعة و النشر،

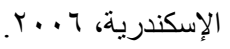

^. علاء الدين محمد عليوة ، مرفت إبر اهيم رخا ، محمد مسعود شرف ، السيد سليمان حماد: التربية الصحية في المجال الرياضي ،

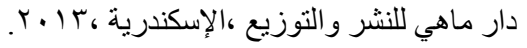

9. كمال عبد الحميد إسماعيل, ابو العلا احمد عبد الفتاح, محمد السيد الأمين: التغذية للرياضيين, مركز الكتاب للنشر, القاهرة, طץ,

.. .9

• ا. . محمد محمد الحماحمي: التغذية والصحة للحياة و الرياضة, مركز الكتاب للنشر , القاهرة , .......

\section{ثانياً :المراجع الأجنبية:}

11. Anita, B.,: The complete guide to sports nutrition, third edition, A \& C black, London, 2000.

12. 12- Barbara J. Hoogenboom, PT, EdD, SCS, ATC,a Jennifer Morris, MSPT,b Chad Morris, MSPT,c and Katharine Schaefer, MSPTd : Nutritional Knowledge and Eating Behaviors of Female, Collegiate Swimmers, N Am J Sports Phys Ther. August; 4(3): 139-148. 2009.

13. 13- Brain, J, S. \& Steven, E, G., : sport physiology for coaches, Human kinetics, U S A, 2006

14. 14- Burke, L.: Practical issues in nutrition for athletes, J, of sports science, Vol 13: 83 - 90, 1995.

15. 15- Daneshvar P, Hariri M, Ghiasvand R, Askari G, Darvishi L, Iraj B, Mashhadi NS: Dietary behaviors and nutritional assessment of young male isfahani wrestlers, Int J Prev Med. ;4(Suppl 1):S48-52. 2013.

16. 16- Frederic, H, M, \& Edwin, F, B., : Essentials of anatomy \& physiology, third edition, prentice hall, New Jersey, U S A, 2003. 
17. 17 - Hinton PS, Sanford TC, Davidson MM, Yakushko OF, Beck NC ;: Nutrient intakes and dietary behaviors of male and female collegiate athletes , Int J Sport Nutr Exerc Metab. Aug;14(4):389-405. 2004.

18. 18-Kang, J., : Bioenergetics primer for exercise science, Human kinetics, U S A, 2008

19. 19-Murphy, S, June P. Youatt, Sharon L. Hoerr, Carol A. Sawyer, Sandra L. Andrews: Nutrition Education Needs and Learning Preferences of Michigan Students in Grades 5, 8, and 11 , Journal of School Health Volume 64, Issue 7, pages 273-278, September ,1994

20. 20- Roland P . Pfeiffer and Brent C . Mangus : Concept of athletic Training, Sixth edition. Jones \& Bartlett Learning. London, 2013

21. 21- Susan Heaney, Helen O'Connor, Scott Michael, Janelle Gifford, : Geraldine Naughton Nutrition knowledge in athletes, International journal of sport nutrition and exercise metabolism (impact factor: 2.01). 06/; 21(3):248-61. 2011.

22. 22- Vinti Davar : Nutritional Knowledge and Attitudes Towards Healthy Eating of College-going Women Hockey Players J Hum Ecol, 37(2): 119-124, 2012. 


\section{الملخص باللغة العربيـة}

الإتجاهات الغذائية و السلوك الغذائى للاعبى كرة السلة بالدورى الممتاز. أســـد علــى أحـــد الكبـكي

قسم تدريب الالعاب الرياضية ـ كلية التربية الرياضية للبنين - جامعة الإسكندرية. - جمهورية مصر العربية الــسيد ســــيمان حمـــــاد

قسم العلوم الحيوية والصحية الرياضية- كلية التربية الرياضية للبنين - جامعة الإسكندرية- جمهورية مصر العربية جمال عبدالناصر يونس محمود

قسم العلوم الحبوية والصحية الرياضية- كلية التربية الرياضية للبنين - جامعة الإسكندرية- جمهورية مصر العربية إن علم التغذية من العلوم التطبيقية التي يعتمد عليها في مجال التربية البدنية والرياضة وقد ارتبطت التغذيـة بممارسـة الرياضـة من أجل الصـة كما ارتبطت التغذية بالمجال الرياضي التنافسي خلال مر احله المتعددة سواء في مرحلة التدريب أو المنافسـة، ففي التدريب تلعب التغذية دوراً هاماً في القدرة على تحمل التدريب وذللك خلال سر عة استعادة الثفاء، ومن الضـروري عند التخطيط للتغذيـة أن يضـع في الاعتبار الاتجاهـات و السلوكيات الغذائية للاعبين، كماأن البرامج الغذائية للرياضبين لا تقل أهمية عن برامج التدريب، حيث أن البرامج الغذائية السليمة في مرحلة معينة تكون أهم من بر امج التدريب، وخاصة في الالعاب الجماعية، وكذلك تظهر أهمية البر امج الغذائية لدى الرياضبين في المعسكرات وقبل و أثناء وبعد المنافسة ، كل ذلك يجب أن يتم تحت إثر اف ومن خلال أخصائي التغذية حتى تترجم عمليات التدريب الفنية إلى نتائج ومستويات يحققها هؤ لاء الرياضيون. و التغذية الصحية تعني إتباع سلوك غذائي و عـادات غذائية سليمة نتيجة لنشـر الوعي الغذائي الصـيح ، كمـا أن الإتجاهـات الغذائية والعـادات و التقاليد الغذائية الخاطئة تلعب دوراً كبيراً في تدهور الحالة الصحية للرياضيين وحدوث بعض أمر اض سوء التغذية حيث أن الإفر اط في تناول الطعام يؤدي إلىى التضـخم البدني وزيـادة وزن الجسم كمـا أن نقص تتـاول الطعـام يؤدي إلى النحافـة ونقص في وزن الجسم ، كمـا إن التغذيـة المتوازنة تعتبر مكون هام في بر امج التدريب الرياضي فالتدريب والتغذية عنصرين أساسيين برتقيان باللاعب إلى التفوق في النشاط الرياضي، ويمكن النظر إلى التغذية بالنسبة للرياضي من زاويتين ، التغذية للمنافسة والتغذية للتدريب. و التغذية ترتبط بعدة عو امل بالغة الأهمية تساعد في تقييم مستوى لاعبي كرة السلة ، ومن هذه العو امل ضبط الوزن، وتخطيط الوجبات الغذائية

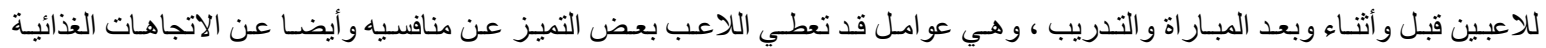
و السلوكيات الغذائية ، كما أن التعود على عادات غذائية صحية سليمة تساعد اللاعبين على الاستشفاء سريعا بعد التدريبات و البطو لات ودن هذ . هذ المنطلق فقد فكر الباحثون في در اسة الاتجاهات الغذائية والسلوك الغذائي للاعبي كرة السلة كأحد أوجه العملية التدريبية والتي يمكن على اثرهـا توجيه العملية التدرييـة للوصـول إلي أعلي المستويات الرياضية الممكنة وقد هدفت الدر اسـة إلى التعرف على الاتجاهـات الغذائيسة والسلوك الغذائي للاعبي كرة السلة بالدوري الممتازو ايضـاً التعرف على العلاقة بين الاتجاهـات الغذائيسة والسلوك الغذائي للاعبي كرة السلة بالدوري الممتاز، وقد أستخدم الباحثون المنهج الوصفي ، وقد بلغ عدد إجمالي أفراد عينة البحث بو لاعب ،تم إختيار عينة البحث من لاعبي كرة السلة من الفرق المشاركة فى الدورة المجمعة التى أقيمت بالصالة المغطاة بالمركز الاوليمبى العسكري بمدينـة الإسكندرية ، مقسمون الى المجموعة الاولى ( ^ץ) لاعبا من الفرق الحاصلة على المر اكز الثثلاث الاولي في بطولة الدورى الممتاز وهي على الترثيب ( سبورتتج - الجزيرة -

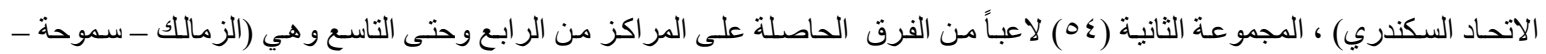

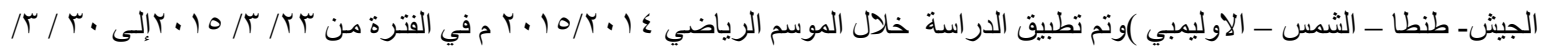
ه 1 • بم وكانت أهم نتائج البحث تفوق لاعبي المستوى العالي والحاصلون على المر اكز الثلاث الاولى بالدوري المتاز في بعض محاور الاتجاهات الغذائية والسلوك الغذائي ، وجود علاقة ارتباط في بعض محاور الاتجاهـات الغذائية و السلوك الغذائى للاعبى كرة السلة بالدورى

الممتاز 
Nutritional Irends and dietary behavior of basketball players Premier League.

\section{Asaad Ali Ahmed Elkiki}

\section{Elsayed Soliman Hammad}

\section{Gmal abdelnasr Yones Mahmod}

The nutrition science of Applied Sciences reliable in the field of physical education and sport have been linked to nutrition exercise for health Sports also been associated with nutrition field athlete competitive through multiple stages, whether in training or competition stage, in training, nutrition plays an important role in the affordability of training and that by restoring a speedy recovery, it is essential when planning for nutrition to take into account the trends of food and behaviors of the players, Kmaon food programs for athletes is as important as training programs, where that sound nutritional programs at some point be more important than training programs, especially in team sports, as well as importance of food programs in athletes in camps and appear before, during and after the competition, all this must be done under the supervision of and through dietitian even translate technical training to achieve results and levels of these athletes.

Health and nutrition mean dieting behavior and eating habits of sound as a result of the deployment of the right nutritional awareness, and the food trends and habits and food traditions wrong play a major role in the deterioration of the health status of athletes and the occurrence of some diseases of malnutrition as overeating leads to physical inflation and increased body weight as The lack of eating leads to thinness and lack of body weight, and balanced nutrition is considered an important component in sports training programs training is nutrition essential elements Ertkien came to excel in sports activity, and can be seen as nutrition for the athlete from two angles, nutrition for competition and nutrition training.

And nutrition linked to several critical factors that help in assessing the level of basketball players, and these factors are weight control, and planning meals for the players before, during and after the game and training, factors that may give a player some stand out from its competitors and also about food trends and food behaviors, and getting used to healthy eating habits help the players to the hospital quickly after workouts and tournaments, and this premise has thought of the researchers in the study of food trends, food and behavior of the basketball players as one of the aspects of the training process, which can be on the track of the training process route to reach the highest possible levels of sports The study aimed to recognize the food trends, food and behavior of basketball players the Premier league and to identify the relationship between dietary trends and food behavior of basketball players the Premier League, researchers have descriptive approach used, the number of total research sample totaled( 92) player, was the research sample of basketball players from the participating teams Selection in the combined cycle, which took place hall-covered military Olympic Center in Alexandria, divided into Group A (38) players from winning the first three centers teams in the Premier League and is on the order (Sporting - Al Jazeera - Al Ittihad), Group B (54) player from winning positions from the fourth until the ninth difference a (Zamalek - Smouha - Aljeich- Tanta - elshamsOlympic) was applied study during the sports season 2014/2015 in the period from 23/03/2015 to30 /03/2015 The main search results outweigh the players and the high level obtaining on the first three positions in the Premier League axes some food trends, food and behavior, there is some correlation in the axes of food and food trends and behavior of the basketball players Premier League 